\title{
Changes of nitric oxide system and lipid peroxidation parameters in the digestive system of rats under conditions of acute stress, and use of nonsteroidal anti-inflammatory drugs
}

\author{
Iryna Fomenko, Tetyana Bondarchuk, Vitaliy Emelyanenko, Natalia Denysenko, \\ Sklyarov Pavlo, Iryna Ilkiv, Roman lesyk, Alexander Sklyarov
}

Department of Biochemistry of Danylo Halytsky Lviv National Medical University, 69 Pekarska Street, 79000 Lviv, Ukrain

\begin{tabular}{l}
\hline ARTICLE INFO \\
\hline Received 07 November 2014 \\
Accepted 12 December 2014 \\
\hline
\end{tabular}

Keywords:

stress,

NSAIDs,

nitric oxide,

lipid peroxidation,

gastrointestinal tract.

\begin{abstract}
The use of nonsteroidal anti-inflammatory drugs (NSAIDs) in combination with being physiologically stressed often occurs in in the course of different pathologies. This situation may result in the alteration of digestive system functioning. The effect of stress brings about changes in the activity of nitric oxide synthase (NOS), arginase, cyclooxygenase (COX) and lipid peroxidation, whereas the use of NSAIDs interrupts the multiple functions of the cell via the inhibition of prostaglandins (PGs) synthesis. Taking into account that NOS and COX-systems are connected in their regulation, the aim of the study was to determine the role played by NOS and lipid peroxidation under conditions of the combined action of NSAIDs and stress. In our study, male rats were used. The NSAIDs (naproxen - a non-selective COX inhibitor, celecoxib - a selective COX-2 blocker, and the compound 2A5DHT (which is the active substance of dual COX, and the lipoxygenase (LOX) inhibitor, darbufelone) were all administered at a dose $10 \mathrm{mg} / \mathrm{kg}$, prior to water restraint stress (WRS). WRS brought about an increase of inducible NOS (iNOS) activity in the intestinal mucosal and muscular membranes, as well as in the pancreas. Because of this, constitutive NOS izoform (cNOS) and arginase activities decreased. Moreover, the MDA concentration increased, indicating the development of oxidative stress. In our work, pretreatment with naproxen, as in the WRS model, engendered a decrease in iNOS activity. What is more, administration of Celecoxib did not change iNOS activity, as compared to WRS alone, and it showed a tendency to reduce lipid peroxidation. In addition, 2A5DHT prior WRS brought about a decrease of iNOS activity, with the subsequent rise of cNOS activity. Of note, MDA concentration decreased in all studied organs, indicating the reduction of lipid peroxidation under the action of the darbufelone active substance.
\end{abstract}

\section{INTRODUCTION}

Although the etiology of different ulcerative diseases of the gastrointestinal tract (GIT) differs, much evidence implicates the crucial role played by the same key factors, stress, NSAIDs and disbiosis, in contributing to the development of lesions in different organs throughout the GIT $[4,7]$.

The exposure to stress is a major risk factor in the pathogenesis of various GIT diseases [4,7], as organs of the GIT are very sensitive to the influence of stress. Stress affects

\section{Corresponding author}

e-mail: biochemistry@meta.ua

tel. +380506905556 the different functions of digestive system, including gastric secretion, gut motility, mucosal permeability, mucosal blood flow and the content of the gastrointestinal microflora [7]. Reactive oxygen species (ROS), which trigger lipid peroxidation, accompany ischemic tissue events and are suggested to be mediators of GIT injuries [8]. Moreover, nitric oxide (NO), overproduced under condition of GIT ulceration, interacts with ROS, producing peroxynitrite, which is one of the most toxic derivatives of NO [9].

NSAIDs' gastrointestinal side-effects are one of the most serious complications in patients taking these drugs [2]. There are three main mechanisms of NSAIDs-induced 
complication in the GIT: inhibition of COX enzymes and cytoprotective PG, membrane permeabilization and the production of additional pro-inflammatory mediators. Selective COX-2 inhibitors (coxibes) were developed in order to reduce the side effects of NSAIDs that are associated mostly with the suppression of the constitutive COX-1 enzyme. However, recent studies using selective COX-1 and COX-2 inhibitors noted an overlapping action of both isoforms, and that both isoforms are involved in homoeostasis processes, just as both are modulators of inflammatory reactions [14]. Furthermore, serious cardiovascular toxicity is associated with the use of selective COX-2 inhibitors [4]. As a result, the search for safe NSAIDs has continued. In the past few decades, several compounds have been developed to block both COX and lipooxygenase (LOX). Dual COX/LOX inhibitors constitute a valuable alternative to classical NSAIDs and selective COX-2 inhibitors for the treatment of inflammatory diseases [10]. Moreover, they appear to be almost exempt from gastrointestinal toxicity. One of the most potent dual inhibitors is darbufelone (with the active substance 2-amino-5-(3,5-ditertbutyl4-hydroxybenzylidene)-thiazol-4-one) [10].

Different NSAIDs are widely use for the treatment of different pathologies. Their use is often accompanied by acute or chronic stress. Both stress and NSAIDs may result in the alteration of digestive system functioning. The purpose of our study was to clarify whether in rats, the combined action of experimental stress and different NSAIDs (conventional, selective COX-2 and dual acting) induces changes in lipid peroxidation and in the nitric oxide (NO) system indices, in organs of the GI tract.

\section{MATERIALS AND METHODS}

Animals. The structure of this study and the experimental procedures performed on the animals were approved by the Ethical Committee of Lviv National Medical University. The experimental procedures were carried out in accordance with international guidelines for the use and care of laboratory animals. Male, outbred Wistar rats weighing 200-220 g were used. They were housed under conditions of controlled temperature $\left(21-22^{\circ} \mathrm{C}\right)$ and light cycle (lights on at $08: 00$ and off at 20:00) and fed standard rat chow and water ad libitum. The rats were fasted for 24 hours prior to the experimental procedures.

Water-immersion restraint stress. The (WRS) model was used to induce stress. The rats were restrained in wire cages and immersed up to the depth of the xiphoid process, in a water bath $\left(23^{\circ} \mathrm{C}\right)$, for 5 hours, to induce gastric mucosal lesions, as previously described [4].

Test drugs. Naproxen, celecoxib and 2A5DHT (which is the active substance of darbufelone) were examined in both models of gastric damage. Before the administration, the drugs were dissolved in a small amount of DMSO, then suspended in $1 \%$ carboxymetylcellulose. Naproxen, celecoxib and 2A5DHT were administered intragastrically (via an orally introduced polyethylene tube) at a single dose $(10 \mathrm{mg} / \mathrm{kg}$; volume of $1 \mathrm{~mL}) 30 \mathrm{~min}$ prior to WRS.

Synthesis of 2-amino-5-(3,5-ditertbutyl-4-hydroxybenzylidene)-thiazol-4-one (2A5DHT). The starting 2-aminothiazol-4-one was obtained according to the method described previously [15]. Elemental analyses $(\mathrm{C}, \mathrm{H}, \mathrm{N})$ was performed using the Perkin-Elmer $2400 \mathrm{CHN}$ analyzer. The analyses indicated by the symbols of the elements or functions were within $\pm 0.4 \%$ of the theoretical values. The ${ }^{1} \mathrm{H}$-NMR spectra were recorded by using a Varian Gemini $400 \mathrm{MHz}$, in a DMSO- $d_{6}+\mathrm{CCl}_{4}$ mixture, employing tetramethylsilane (TMS) as an internal standard. Chemical shifts are reported in ppm units with use of the $\delta$ scale.

Mixtures of 2-aminothiazol-4-one (5 mmol), 3,5-ditertbutyl-4-hydroxybenzaldehyde $(5.5 \mathrm{mmol})$ and anhydrous sodium acetate $(5 \mathrm{mmol})$ were refluxed for $3 \mathrm{~h}$ in glacial acetic acid $(10 \mathrm{ml})$. The obtained powder was filtered off, washed with water and recrystallized with glacial acetic acid (Fig. 1). The yield was: 68\%, $1 \mathrm{H}$ NMR (300 MHz, DMSOd6+CCl4): $\delta$ [ppm] 9.81, 9.30, 9.03 (s, br.s, s, 2H, NH2); $7.67(\mathrm{~s}, 1 \mathrm{H}, \mathrm{OH}) ; 7.53(\mathrm{~s}, 1 \mathrm{H}, \mathrm{CH}) ; 7.35(\mathrm{~s}, 2 \mathrm{H}$, arom $) ; 1.40$ $(\mathrm{s}, 18 \mathrm{H}, 2 * \mathrm{t}-\mathrm{Bu})$.

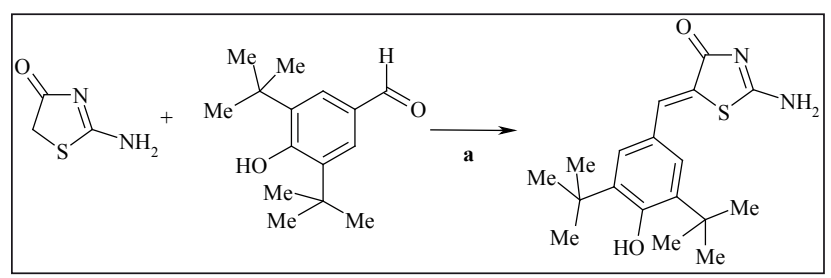

Figure 1. Synthesis of 2-amino-5-(3,5-ditertbutyl-4-hydroxybenzylidene)-thiazol-4-one (2A5DHT). Reagents, conditions and yields: (a) AcONa, $\mathrm{AcOH}$, reflux 3h, 68\%

Study protocol. The rats were randomly placed into 5 groups ( $\mathrm{n}=8$ in each group). Group 1 consisted of rats treated only with the vehicle (Control). The other groups of rats were pretreated with vehicle (group 2), naproxen (group 3), celecoxib (group 4) and 2A5DHT (group 5). The $2^{\text {nd }}-5^{\text {th }}$ groups were subjected to WRS for $30 \mathrm{~min}$ after treatment with the above-mentioned drugs.

The rats were then anaesthetized with $1 \mathrm{ml}$ of urethane at a dose of $1.1 \mathrm{mg} / \mathrm{kg}$ injected intraperitoneally, and killed by cervical dislocation. A blood sample from the cervical vessel was immediately collected into vials containing $0.1 \mathrm{~mL}$ of heparin. The small and large intestines were then harvested, opened and washed in isotonic sodium chloride solution. Samples of the mucosal membranes of the small and large intestines, the muscular membrane of the large intestine and samples of pancreatic tissue were collected and homogenized in saline (1:4), centrifuged at 2,000 $\mathrm{g}$ and the supernatant was used for the measurement of various biochemical parameters (see below).

Biochemical assessment. Lipid peroxidation levels were determined as malonic dialdehyde (MDA) concentration in homogenates of the mucosal and the muscle membranes, as well as the pancreas, and were measured by the method described in detail previously [13]. NOS activity (iNOS and cNOS) [13] was expressed in nmol NADPH/min'g of protein, while Arginase activity was determined by the method [5], and was expressed in $\mu \mathrm{mol} / \mathrm{min} \cdot \mathrm{mg}$ of protein. The concentration of L-arginine in the plasma samples was measured according to the method of Alejnikova, previously described [4]. 
Statistical analyses. The data are expressed as mean \pm SEM. Statistical comparisons were performed with Student's $t$ test. Comparisons involving more than two groups were performed by a one-way analysis of variance (ANOVA). Differences with $p$-value $<0.05$ were considered as significant.

\section{RESULTS}

Our results revealed that there was a low concentration of MDA and significant activity of cNOS throughout the GIT of vehicle-treated rats, while iNOS activity was low (Tab. 1). This is consistent with the previously reported data $[3,4,13]$.

The effect of being subjected to WRS resulted in a considerable increase of MDA concentration in all studied organs of the GIT (by 18\% (p<0.01), 40\% (p<0.01), $17 \%(\mathrm{p}<0.05)$ and $22 \%(\mathrm{p}<0.05)$ in the pancreas and mucosal membranes of the small and large intestines, and the muscular membrane of the large intestine, respectively). We can also confirm that the stomach is the organ most sensitive to the influence of oxidative stress as induced by WRS, because, as was previously revealed [4], lesions had developed only in the stomach. It should be also pointed out that the concentration of MDA was initially much lower in the muscular membrane of the large intestine and higher in the pancreas.

Subjecting the rats to WRS resulted in a considerable increase of iNOS activity $(\mathrm{p}<0.01)$, and a concomitant decrease of eNOS and arginase activities. The highest rate of changes was seen in the large intestine, where iNOS activity increased 4.6 fold $(\mathrm{p}<0.01)$ in the mucosal membrane, and 5.9 fold $(p<0.01)$ in the muscular membrane. These results are likely a consequence of the increased activation of NO synthases, increased concentrations of L-arginine (the substrate for NOS), and a decrease in the plasma $(\mathrm{p}<0.05)$ (Fig. 2).

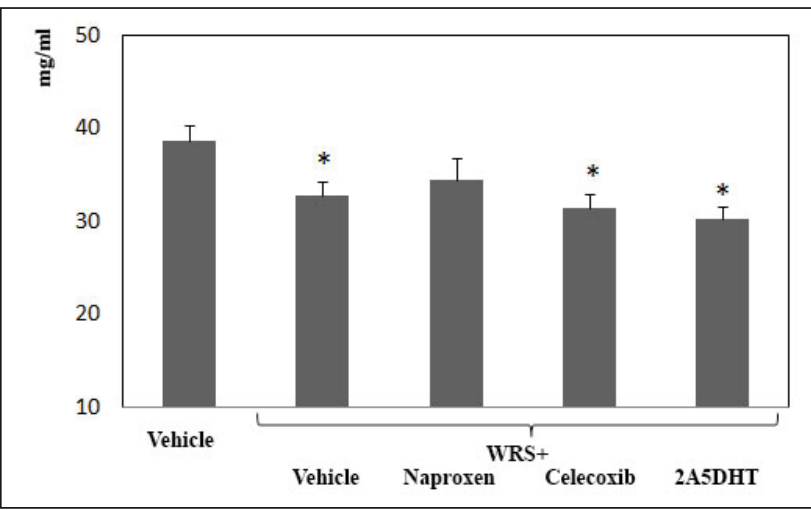

Figure 2. Concentration of L-arginine in the blood of the rats of the different groups: vehicle-treated, vehicle + water restraint stress (WRS), naproxen +WRS, celecoxib + WRS, 2A5DHT+WRS Results are expressed as the mean \pm SEM for 8 rats per group; ${ }^{*} \mathrm{p}<0.05$, versus the indices in vehicle + WRS

Administration of naproxen prior to WRS resulted in similar changes within all studied organs. These changes were manifested by a significant decrease of iNOS enzyme activity, as compared to the effect in the vehicle + WRS group. A statistically significant decrease of cNOS activity was only seen in the the large intestine $(p<0.05)$. However, the activity of arginase remained lower than normal, while MDA concentration practically did not change significantly.

The indices of the NO synthase system in the groups of rats pretreated with celecoxib before WRS did not differ subsequently from those in the group vehicle + WRS, in all studied organs - with the exception of the pancreas parameters, where the activity of iNOS decreased (by $49 \%$, $\mathrm{p}<0.05)$. Note: an evident tendency existed for the decrease of MDA concentration in the pancreas and in the small intestine, however this concentration remained practically unchanged in the large intestine.

Table 1. The effect of nonsteroidal anti-inflammatory drugs (nonselective COX inhibitor - naproxen, selective cyclooxygenase-2 blocker - celecoxib, and dual-acting - 2A5DHT) under water restraint stress on the concentration of malonic dialdehyde and the activities of nitric oxide synthases: inducible - iNOS and constitutive - cNOS and arginase, in the organs of the gastrointestinal tract (GIT)

\begin{tabular}{|c|c|c|c|c|c|}
\hline $\begin{array}{c}\text { Group } \\
\text { of } \\
\text { animals }\end{array}$ & \begin{tabular}{|c|} 
Organs of \\
gastrointestinal \\
tract
\end{tabular} & $\begin{array}{c}\text { Malonic } \\
\text { dialdehyde } \\
(\mu \mathrm{mol} / \mathrm{g}) \\
\end{array}$ & $\begin{array}{c}\mathrm{iNOS} \\
(\mathrm{nmol} / \mathrm{min} \\
\mathrm{g})\end{array}$ & $\begin{array}{c}\mathrm{cNOS} \\
(\mathrm{nmol} / \mathrm{min} \\
\mathrm{g})\end{array}$ & $\begin{array}{c}\text { Arginase } \\
(\mu \mathrm{mol} / \mathrm{min} \\
\mathrm{g})\end{array}$ \\
\hline \multirow{4}{*}{ 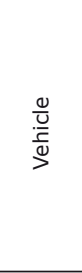 } & Pancreas & $409.0 \pm 4.0$ & $0.13 \pm 0.01$ & $0.48 \pm 0.04$ & $0.29 \pm 0.01$ \\
\hline & $\begin{array}{c}\text { Mucosal } \\
\text { membrane of } \\
\text { small intestine }\end{array}$ & $191.5 \pm 4.1$ & $0.24 \pm 0.02$ & $0.58 \pm 0.04$ & $0.32 \pm 0.01$ \\
\hline & $\begin{array}{c}\text { Mucosal } \\
\text { membrane of } \\
\text { large intestine }\end{array}$ & $240.7 \pm 1.6$ & $0.23 \pm 0.03$ & $0.53 \pm 0.03$ & $0.38 \pm 0.01$ \\
\hline & $\begin{array}{c}\text { Muscular } \\
\text { membrane of } \\
\text { large intestine }\end{array}$ & $107.2 \pm 10.3$ & $0.18 \pm 0.04$ & $0.33 \pm 0.09$ & $0.31 \pm 0 / 02$ \\
\hline \multirow{4}{*}{ 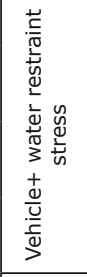 } & Pancreas & $482.8 \pm 1.1^{* *}$ & $* 0.76 \pm 0.07 * *$ & $0.16 \pm 0.03 *$ & $0.24 \pm 0.01$ \\
\hline & $\begin{array}{c}\text { Mucosal } \\
\text { membrane of } \\
\text { small intestine }\end{array}$ & $268.0 \pm 2.6 * *$ & $* 0.69 \pm 0.04 * *$ & $0.24 \pm 0.05 *$ & $0.21 \pm 0.01 *$ \\
\hline & $\begin{array}{c}\text { Mucosal } \\
\text { membrane of } \\
\text { large intestine }\end{array}$ & $278.2 \pm 1,73 *$ & $* 1.05 \pm 0.09 * *$ & $0,17 \pm 0.03 * *$ & $0,18 \pm 0.01 * *$ \\
\hline & $\begin{array}{c}\text { Muscular } \\
\text { membrane of } \\
\text { large intestine }\end{array}$ & $131 \pm 5.0 *$ & $1.07 \pm 0.18^{*}$ & $0.22 \pm 0.09 *$ & $0.26 \pm 0.06$ \\
\hline \multirow{4}{*}{ 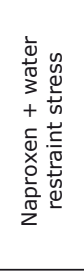 } & Pancreas & $478.8 \pm 3.4$ & $0.48 \pm 0.06^{\#}$ & $0.27 \pm 0.03$ & $0.23 \pm 0.02$ \\
\hline & $\begin{array}{c}\text { Mucosal } \\
\text { membrane of } \\
\text { small intestine }\end{array}$ & $221.3 \pm 1.65^{\#}$ & $\# 0.49 \pm 0.01^{\#}$ & $0.26 \pm 0.04$ & $0.22 \pm 0.01$ \\
\hline & $\begin{array}{c}\text { Mucosal } \\
\text { membrane of } \\
\text { large intestine }\end{array}$ & $277.1 \pm 2.8$ & $0.59 \pm 0.01^{\# \#}$ & $0.33 \pm 0.03^{\#}$ & $0.22 \pm 0.01$ \\
\hline & $\begin{array}{c}\text { Muscular } \\
\text { membrane of } \\
\text { large intestine }\end{array}$ & $129.6 \pm 3.5$ & $0.46 \pm 0.12$ & $0.24 \pm 0.16$ & $0.19 \pm 0.07$ \\
\hline \multirow{4}{*}{ 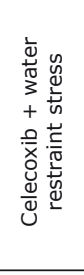 } & Pancreas & $480.0 \pm 2.36$ & $0.37 \pm 0.05^{\#}$ & $0.24 \pm 0.04^{\#}$ & $0.21 \pm 0.01$ \\
\hline & $\begin{array}{c}\text { Mucosal } \\
\text { membrane of } \\
\text { small intestine }\end{array}$ & $226.0 \pm 2.58^{\#}$ & $\# \quad 0.69 \pm 0.05$ & $0.29 \pm 0.04$ & $0.21 \pm 0.01$ \\
\hline & $\begin{array}{c}\text { Mucosal } \\
\text { membrane of } \\
\text { large intestine }\end{array}$ & $280.7 \pm 2.3$ & $1.2 \pm 0.02$ & $0.39 \pm 0.04^{*}$ & $0.24 \pm 0.01$ \\
\hline & $\begin{array}{c}\text { Muscular } \\
\text { membrane of } \\
\text { large intestine }\end{array}$ & $124.5 \pm 5.0$ & $1.17 \pm 0.06$ & $0.36 \pm 0.04^{\#}$ & $0.24 \pm 0.02$ \\
\hline \multirow{4}{*}{ 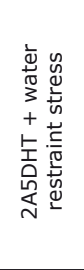 } & Pancreas & $460.7 \pm 1.9$ & $0.31 \pm 0.06^{\#}$ & $0.25 \pm 0.04$ \# & $0.24 \pm 0.03$ \\
\hline & $\begin{array}{c}\text { Mucosal } \\
\text { membrane of } \\
\text { small intestine }\end{array}$ & $215.7 \pm 4.5^{\#}$ & $0.69 \pm 0.05$ & $0.44 \pm 0.07^{\#}$ & $0.26 \pm 0.02$ \\
\hline & $\begin{array}{c}\text { Mucosal } \\
\text { membrane of } \\
\text { large intestine }\end{array}$ & $275.5 \pm 1.5$ & $0.78 \pm 0.45^{\#}$ & $0.41 \pm 0.04^{\#}$ & $0.27 \pm 0.02$ \\
\hline & $\begin{array}{c}\text { Muscular } \\
\text { membrane of } \\
\text { large intestine }\end{array}$ & $128.0 \pm 3.5$ & $0.77 \pm 0.06$ & $0.38 \pm 0.06$ & $0.26 \pm 0.02$ \\
\hline
\end{tabular}

Results are expressed as the mean \pm SEM for 8 rats per each group; $* \mathrm{p}<0.05, * * \mathrm{p}<0.01$ versus the indices in vehicle $+\mathrm{WRS} ;{ }^{*} \mathrm{p}<0.05$, ${ }^{\#} \mathrm{p}<0.01$, versus the indices of vehicle-treated rats (data were compared using Student's $t$ test and ANOVA, differences with $\mathrm{p}$-value $<0.05$ were considered as significant).

Administration of the dual COX/LOX inhibitor 2A5DHT prior to WRS brought about a decrease of iNOS activity 
( $\mathrm{p}<0.05$ for all studied tissues excepting the small intestine), as compared to vehicle + WRS, with a subsequent rise of cNOS activity $(\mathrm{p}<0.05)$, and a tendency towards an increase of arginase activity. However, MDA concentration decreased in all the studied organs. This indicates a reduction of lipid peroxidation under the action of the darbufelone active substance.

\section{DISCUSSION}

This study was designed to show the role of lipid peroxidation and of the NO system in the GIT, under the combined action of stress and NSAIDs. In the present study, rats, first fasted and then exposed to WRS for 5 hours, showed a rise of MDA concentration that conforms to the previously reported data $[3,4]$. This effect is probably due to an increase in the production of catecholamines by the super-renal glands, which leads to vasoconstriction and local ischemia, and, subsequently, to gastric lesions [4,7]. In our study, no visual changes were noticed in the intestinal mucosa, as well as in the pancreatic tissue, however lipid peroxidation was also increased. What is more, in addition to oxidative stress, iNOS expression and activity rose in all studied tissues of the GIT. This effect arranges conditions for the development of ulcerative lesions, not only in stomach, but also in the small and large intestines. Thus, we may speculate that a rise in concentration of MDA, along with the activity of iNOS, indicates pre-inflammatory conditions in the organs of the GIT.

Stress is much more complicated notion than only the hyperproduction of chatecholamines. Glucocorticoid production also increases under conditions of stress [2]. These hormones inhibit phospholipase $\mathrm{A}_{2}$, an enzyme responsible for the release of arachidonic acid, which serves as a substrate for the COX enzymes. Thus, WRS induces a significant inhibition of PGE generation by the gastric mucosa [4].

Pretreatment with naproxen in the WRS model in rats brought about a decrease of NOS activity (both isoforms). The same tendency was noticed in all studied tissues. These effects, which are induced by naproxen, can be explained by its topical and systemic activity [12]. Such activity is connected with the nonselective inhibition of COX, and with changes in permeability induced by changes in membrane hydrophylity, fluidity, thickness, bending stiffness and pore formation [12]. We suggest that the action of naproxen sharply reduces PG synthesis when glucocorticoids are over-produced as a response to stress. Such an opinion corresponds that of Brzozovski et al. [1]. In their study, nonselective COX inhibition was induced by the administration of indomethacin at a dose of $5 \mathrm{mg} / \mathrm{kg}$. Moreover, indomethacin inhibited generation of endogenous $\mathrm{PGE}_{2}$ by about $85 \%$.

The deficiency of PGs under the combined action of stress (glucocorticoids) and the COX-1/COX-2 nonselective inhibitor, naproxen, may play a crucial role in bringing about damage to the tissues of the GIT by suppressing the adaptative cytoprotection against stress. The evidence towards this effect allows us to suggest that the relationship between COX-1 and iNOS was underestimated. However, the close connection of COX-2 and iNOS was described previously [11].
The same dose $(10 \mathrm{mg} / \mathrm{kg})$ of the COX-2 inhibitor, celecoxib, practically did not affect iNOS activity. Indeed, in our experiment, the administration of celecoxib inhibited iNOS activity only in the pancreas. Previous literature saw that WRS significantly decreases the expression of COX-2 and iNOS in the gastric mucosa. Moreover, such literature suggests that COX-2 selective inhibition displayed cytoprotective activity in the pancreas of caerulein-induced rats [6].

The lipoxygenase (LOX) pathway is known to play an important role in inflammation. Leucotriens and lipoxins produced via LOX activity are associated with leucocytes activation and adhesion to the vascular endothelium. Thus, they can bring about damage in the GIT. Experimental data support the postulate that COX inhibition with NSAIDs, besides inducing a reduction in the synthesis of PGs, diverts arachidonate to the 5-LOX pathway, hence increasing the formation of leucotriens [10]. This brings about vasoconstriction, and increases the formation of reactive oxygen radicals from the peroxidative cleavage of hydroxyeicosatetraenoic acids. This then causes further mucosal injury. Thus, compounds that combine COX/LOX inhibition are potentially an alternative to classical NSAIDs and to selective COX-2 inhibitors. Dual inhibitors, by acting on the two major arachidonic acid metabolic pathways (COX and LOX), possess a wider range of anti-inflammatory activity [10]. Beyond this, dual inhibitors appear to be almost exempt from gastric and cardiovascular toxicity, which is the most troublesome side effect of COX inhibitors. In our experiments, the dual acting COX/LOX inhibitor, 2A5DHT, decreased the concentration of MDA and the activity of iNOS. What is more, it was previously shown that it possesses reduced gastrotoxicity under condition of WRS [3]. For this reason, dual COX/LOX inhibitors may have beneficial effects upon the organism, as compared to non-selective or selective COX-inhibitors, under conditions of acute stress.

\section{CONCLUSION}

WRS in rats was accompanied by the activation of iNOS activity and the development of oxidative stress manifested by an increase of MDA concentration in the intestinal mucosal and muscular membranes, as well as in pancreas. Pretreatment with a nonselective COX inhibitor (naproxen) decreased iNOS activity in all studied organs. The COX-2 selective inhibitor, celecoxib, did not change the iNOS activity in the WRS model, however, it did reduce the lipid peroxidation. Of note, dual COX-2/5-LOX inhibition by 2A5DHT decreased iNOS activity and the concentration of MDA. For this reason, dual COX/LOX inhibitors may have beneficial effects on the organism, as compared to nonselective or selective COX-inhibitors, under conditions of acute stress.

\section{ACKNOWLEDGMENTS}

The authors would like to thank Professor John L Wallace (Inflammation Research Network, University of Calgary) for providing us with reagents (naproxen and celecoxib) for our investigations.

Our special thanks are also due to Dr. D. Havryluk for his help in the synthesis of 2A5DHT. 


\section{REFERENCES}

1. Brzozowski T. et al.: Physiological mediators in nonsteroidal antiinflammatory drugs (NSAIDs)-induced impairment of gastric mucosal defense and adaptation. Focus on nitric oxide and lipoxins. J Physiol Pharmacol., 59, 2, 2008.

2. Filaretova L.: Gastroprotective role of glucocorticoids during NSAID-induced gastropathy. Curr Pharm Des., 19, 29, 2013.

3. Fomenko I.S. et al.: Parameters of NO synthase system of gastric mucosa in rats under stress conditions and inhibition of cyclooxygenase. Fiziol Zh., 60, 2, 2014.

4. Fomenko I. et al.: Effects of conventional and hydrogen sulfidereleasing non-steroidal anti-inflammatory drugs in rats with stressinduced and epinephrine-induced gastric damage. Stress, 17(6), 528, 2014.

5. Geyer J.W., Dabich D.: Rapid method for determination of arginase activity in tissue homogenates. Anal Biochem., 39(2), 412, 1971

6. Jaworek J. et al.: Involvement of cyclooxygenase-derived prostaglandin E2 and nitric oxide in the protection of rat pancreas afforded by low dose of lipopolysaccharide. J Physiol Pharmacol., 52, 1, 2001.

7. Konturek P.C. et al.: Gastric ulcer healing and stress-lesion preventive properties of pioglitazone are attenuated in diabetic rats. J Physiol Pharmacol., 61, 4, 2010.
8. Kudryavtsev K.V. et al.: Pharmacological correction of stressinduced gastric ulceration by novel small-molecule agents with antioxidant profile. Scientific World Journal, Article ID 217039, 2014.

9. Lunberg J.O., Weitzberg E.: Biology of nitrogen oxides in the gastrointestinal tract. Gut, 62(4), 616, 2013.

10. Martel-Pelletier J., Lajeunesse D., Reboul P.: Therapeutic role of dual inhibitors of 5-LOX and COX, selective and non-selective nonsteroidal anti-inflammatory drugs. Ann Rheum Dis, 62(6), 501, 2003.

11. Mollace $\mathrm{V}$ et al. Modulation of prostaglandin biosynthesis by nitric oxide and nitric oxide donors. Pharmacol Rev., 57(2),217, 2005.

12. Musumba C., Pritchard D.M., Pirmohamed M.: Review article: cellular and molecular mechanisms of NSAID-induced peptic ulcers. Aliment Pharmacol Ther, 30(6), 517, 2009.

13. Sklyarov A.Y., Panasyuk N.B., Fomenko I.S.: Role of nitric oxidesynthase and cyclooxygenase/lipooxygenase systems in development of experimental ulcerative colitis. J Physiol Pharmacol., 62, 65, 2011.

14. Takeuchi K.: Pathogenesis of NSAID-induced gastric damage: importance of cyclooxygenase inhibition and gastric hypermotility. World J Gastroenterol. 18, 18, 2012.

15. Turkevych N.M.: Vvedenskij V.M., Petlichnaya L.P. Ukr. Khim. Zh. (Russ. Ed.), 1961. 